Article

\title{
Significant association of thrombocytopenia with chronic active hepatitis $B$ virus infection in a tertiary care hospital of an intermediate prevalence $\mathrm{HBV}$ country
}

\author{
Muayad A. Merza ${ }^{1 *}$, Sagvan Kareem Taha ${ }^{1}$, Sara Muhsin Ibrahim² ${ }^{2}$ Ahmed Tayar Sadeeq ${ }^{2}$ and Mahabad R. \\ Abdulrahman ${ }^{2}$ \\ ${ }^{1}$ Azadi Teaching Hospital, Department of Internal Medicine, College of Pharmacy, University of Duhok, \\ Duhok, Kurdistan Region, Iraq \\ ${ }^{2}$ Obstetrics and Gynecology hospital, Department of Obstetrics and Gynecology, University of Duhok, Duhok, \\ Kurdistan Region, Iraq \\ *Corresponding author: Dr. Muayad A. Merza, Assist Prof, Azadi Teaching Hospital, Department of Internal \\ Medicine, College of Medicine, University of Duhok, Azadi Hospital Street, Duhok, Kurdistan Region, Iraq. E- \\ mail: muayad.merza@uod.ac
}

Received: 09 August 2019/Accepted: 17 September 2019/ Published: 30 September 2019

\begin{abstract}
Thrombocytopenia is a relatively uncommon extra-hepatic manifestation of uncomplicated chronic hepatitis B virus (HBV) infection. This study has two aims: to assess the prevalence of thrombocytopenia in non-cirrhotic patients with chronic hepatitis B (CHB); and to determine the association of certain variables with thrombocytopenia in Duhok province. It is a case control study conducted in Azadi Teaching Hospital during June 2016 - May 2019. Chronic active hepatitis B was defined according to the following parameters: the presence of detectable hepatitis B surface antigen (HBsAg) in the blood longer than six months, positive or negative $\mathrm{HBeAg}, \mathrm{HBV}-\mathrm{DNA}$ level >2000 IU/ml, elevated ALT, and/or at least moderate histopathological

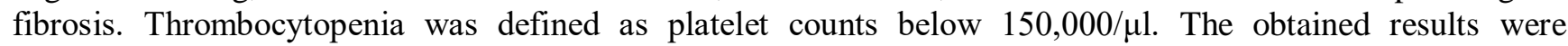
analyzed by entering data into Microsoft Excel 2010. A total of 379 CHB patients and 200 cases as control were enrolled in this study. Their mean ages were $33.62 \pm 14.48$ and $40.72 \pm 18.56$ for HBV and control cases, respectively. There were 236 (62.27\%) males in the HBV patients and $109(54.50 \%)$ males in the control group. Comparing both groups, significant association was found between HBV and younger age, cigarette smoking, and alcohol consumption. Chronic active hepatitis B without liver cirrhosis was strongly associated with an increased rate of thrombocytopenia. This finding is paramount as it is statistically significant $(P=0.042)$. Significant association with younger age and Syrian nationality was found more in CHB patients with thrombocytopenia compared to non-thrombocytopenic. In conclusion, chronic active hepatitis B is strongly associated with thrombocytopenia. As hypersplenism resulting from liver cirrhosis was excluded in our patients, the cause of thrombocytopenia is due to other mechanisms. Therefore, it is important to consider CHB in the differential diagnosis of patients presenting with isolated thrombocytopenia. Older age and Syrian nationality were predictors for developing thrombocytopenia in chronic active HBV infection.
\end{abstract}

Keywords: chronic hepatitis B; thrombocytopenia; association

\section{Introduction}

Hepatitis B virus (HBV) infection is a serious public health problem as it may cause life threatening complications such as liver cirrhosis and hepatocellular carcinoma. Globally, approximately 350 - 400 million people are chronically infected with $\mathrm{HBV}$, and more than 600,000 deaths occur annually as sequel of the infection and its complications (Schweitzer et al., 2015).

In adults, the risk of developing chronic hepatitis B (CHB) infection after an acute episode is about 5\%-10\% (Dunn et al., 2009). The clinical course of chronic HBV infection is diverse, ranging from an inactive carrier 
state to active hepatitis (Marcellin et al., 2005). Extra-hepatic manifestations can occur in about $20 \%$ of patients with acute and CHB and are believed to be mediated by circulating immune complexes (Cacoub et al., 2005). The most common documented extra-hepatic manifestations are sensorimotor neuropathies, arthralgias, myalgias, glomerulonephritis, Sjogren's syndrome, Raynaud's syndrome, and uveitis (Cacoub et al., 2005). Thrombocytopenia is a relatively uncommon extra-hepatic manifestation of uncomplicated chronic HBV infection (Mitchell et al., 2016). Thrombocytopenia, a platelet count $<150,000 / \mathrm{ul}$, is a common laboratory finding, which often needs further investigations and follow ups (Gauer and Braun, 2012) .The most common infectious causes of thrombocytopenia are cytomegalovirus, Epstein-Barr virus, Helicobacter pylori, hepatitis C virus, human immunodeficiency virus, varicella-zoster virus infectious (Gauer and Braun, 2012).

In HBV infection, the pathogenesis of thrombocytopenia is not well known. However, in advanced HBV infection it is mostly attributed to hypersplensim secondary to portal hypertension (Mitchell et al., 2016). Other less common mechanisms of thrombocytopenia in chronic viral hepatitis might be associated with impaired platelet production as a result of suppressed thrombopoietin synthesis, increased platelet destruction, anti-retroviral treatment, and direct damage to megakaryocytes and platelets by viruses (Bano et al., 2016; Gauer and Braun, 2012). As CHB related advanced liver disease is vaguely associated with thrombocytopenia, this study has had been considered imperative. In short, this study has two aims: to assess the prevalence of thrombocytopenia in non-cirrhotic patients with $\mathrm{CHB}$; and to determine the association of certain demographics and health related conditions with thrombocytopenia in Duhok province.

\section{Patients and Methods}

\subsection{Setting}

The viral hepatitis clinic is a specialized center in Azadi Teaching Hospital, for managing all viral hepatitis patients. All patients with chronic HBV visit the center on regular intervals according to the treating physician's advice. The demographic and clinical information of the patients were collected in standardized case files.

\subsection{Study design and patients}

All patients during June 2016 - May 2019 were enrolled in this study and were compared with control group from general clinical practice settings. This study was approved by the ethical committee of Kurdistan Board for Medical Specialties. An informed written consent was obtained from all participants. The patients' data were retrieved from the patients' case notes in the registry unit of the viral hepatitis clinic.

Chronic active hepatitis B was defined according to the following parameters: the presence of detectable hepatitis B surface antigen (HBsAg) in the blood longer than six months, positive or negative $\mathrm{HBeAg}, \mathrm{HBV}$ DNA level >2000 IU/ml, elevated ALT, and/or at least moderate histopathological fibrosis (EASL, 2017). Patients with compensated or decompensated liver cirrhosis were excluded based on clinical, laboratory, and imaging studies. Platelet counts were recorded from both patients and control groups. Thrombocytopenia was defined as platelet counts below $150,000 / \mu 1$. Previous history of thrombocytopenia was an exclusion criterion for both patients and controls. In CHB patients, the clinical parameters based on platelet levels were analyzed for possible association with age, gender, smoking habit, alcohol consumption, and nationality.

\subsection{Statistical analysis}

The obtained results were analyzed by entering data in a binary format using Microsoft Excel 2010 Spreadsheets. A p value $\leq 0.05$ was considered statistically significant.

\section{Results}

A total of $379 \mathrm{CHB}$ patients and 200 cases as control were enrolled in this study. Their mean ages were $33.62 \pm$ 14.48 and $40.72 \pm 18.56$ for HBV and control cases, respectively. There were $236(62.27 \%)$ males in the HBV patients and $109(54.50 \%)$ males in the control group. The characteristics of both groups are shown in Table 1. 
Table 1. Characteristics of the patients and control group.

\begin{tabular}{|c|c|c|c|c|c|c|}
\hline \multicolumn{2}{|l|}{ Variable } & \multirow{2}{*}{$\begin{array}{l}\text { HBV (no. }=\mathbf{3 7 9}) \\
\text { No. }(\boldsymbol{\%}) \\
33.62 \pm 14.48 \\
\end{array}$} & \multirow{2}{*}{$\begin{array}{l}\text { Control }(\text { no. }=\mathbf{~ 2 0 0}) \\
\text { No. }(\%) \\
40.72 \pm 18.56 \\
\end{array}$} & \multirow{2}{*}{$\begin{array}{l}\text { OR } \\
7.100\end{array}$} & \multirow{2}{*}{$\begin{array}{l}\mathbf{9 5 \%} \mathbf{C I} \\
4.3526 \text { to } 9.8474 \\
\end{array}$} & \multirow{2}{*}{$\begin{array}{l}\text { P value } \\
0.0001 \\
\end{array}$} \\
\hline Age & $($ Mean $\pm \mathrm{SD})$ & & & & & \\
\hline \multirow[b]{2}{*}{ Sex } & Male & $236(62.27)$ & $109(54.50)$ & \multirow{2}{*}{1.378} & \multirow{2}{*}{$0.974-1.950$} & \multirow{2}{*}{0.075} \\
\hline & Female & $143(37.73)$ & $91(45.50)$ & & & \\
\hline \multirow[b]{2}{*}{ Smoker } & Yes & $223(58.84)$ & $77(38.50)$ & \multirow{2}{*}{2.283} & \multirow{2}{*}{$1.608-3.243$} & \multirow{2}{*}{0.000} \\
\hline & No & $156(41.16)$ & $123(61.50)$ & & & \\
\hline \multirow{2}{*}{ Alcohol } & Yes & $89(23.48)$ & $26(13.00)$ & \multirow{2}{*}{2.954} & \multirow{2}{*}{$1.275-3.305$} & \multirow{2}{*}{0.003} \\
\hline & No & $290(76.52)$ & $174(87.00)$ & & & \\
\hline \multirow{2}{*}{ Nationality } & Iraqi & 356 (93.93) & $193(96.50$ & \multirow{2}{*}{1.781} & \multirow{2}{*}{$0.751-4.226$} & \multirow{2}{*}{0.238} \\
\hline & Syria & $23(6.07)$ & $7(3.50)$ & & & \\
\hline
\end{tabular}

The prevalence rate of thrombocytopenia was higher among CHB patients (Table 2).

Table 2. Prevalence of thrombocytopenia among CHB and control group.

\begin{tabular}{|c|c|l|l|l|l|}
\hline \multicolumn{2}{|c|}{ Variable } & $\begin{array}{l}\text { CHB* (no. = 379) } \\
\text { No. (\%) }\end{array}$ & $\begin{array}{l}\text { CG**(no. = 200) } \\
\text { No. (\%) }\end{array}$ & OR (95\% CI) & $\begin{array}{l}\text { P } \\
\text { value }\end{array}$ \\
\hline \multirow{2}{*}{ Thrombocytopenia } & Yes & $16(4.22 \%)$ & $2(1.00 \%)$ & \multirow{2}{*}{$4.364(0.993$ to 19.172$)$} & 0.042 \\
\cline { 2 - 6 } & No & $363(95.78 \%)$ & $198(99.00 \%)$ & & \\
\hline
\end{tabular}

*CHB: chronic hepatitis B

**CG: control group

Table 3 demonstrates a comparison of baseline characteristics between CHB with and without thrombocytopenia showed significant association with younger age and Syrian nationality.

Table 3. Comparison of baseline characteristics of chronic hepatitis B according to platelet count level.

\begin{tabular}{|c|c|c|c|c|c|c|}
\hline \multicolumn{2}{|l|}{ Variable } & \multirow{2}{*}{$\begin{array}{l}\text { CHB with } \\
\text { thrombocytopenia } \\
\text { (no. = 16) } \\
\text { No. }(\%) \\
49.56 \pm 17.16 \\
\end{array}$} & \multirow{2}{*}{$\begin{array}{l}\begin{array}{l}\text { CHB without } \\
\text { thrombocytopenia } \\
\text { (no. }=\mathbf{3 6 3}) \\
\text { No. }(\%)\end{array} \\
32.92 \pm 13.94\end{array}$} & \multirow{2}{*}{$\begin{array}{l}\text { OR } \\
16.6700 \\
\end{array}$} & \multirow{2}{*}{$\begin{array}{l}\text { 95\% CI } \\
9.5967-23.7433 \\
\end{array}$} & \multirow{2}{*}{$\begin{array}{l}\text { P value } \\
0.0001 \\
\end{array}$} \\
\hline age & $($ Mean $\pm \mathrm{SD})$ & & & & & \\
\hline \multirow{2}{*}{ Sex } & Male & $13(81.25 \%)$ & $223(61.43 \%)$ & \multirow{2}{*}{2.720} & \multirow{2}{*}{$0.762-9.717$} & \multirow{2}{*}{0.123} \\
\hline & Female & $3(18.75 \%)$ & $140(38.57 \%)$ & & & \\
\hline \multirow{2}{*}{ Smoker } & Yes & $13(81.25 \%)$ & $210(57.85 \%)$ & \multirow{2}{*}{3.157} & \multirow{2}{*}{$0.884-11.271$} & \multirow{2}{*}{0.072} \\
\hline & No & $3(18.75 \%)$ & $153(42.15 \%)$ & & & \\
\hline \multirow{2}{*}{ Alcohol } & Yes & $7(43.75 \%)$ & $82(22.59 \%)$ & \multirow{2}{*}{2.66} & \multirow{2}{*}{$0.963-7.376$} & \multirow{2}{*}{0.068} \\
\hline & No & $9(56.25 \%)$ & $281(77.41 \%)$ & & & \\
\hline \multirow{2}{*}{ Nationality } & Iraqi & $12(75.00 \%)$ & $344(94.77 \%)$ & \multirow{2}{*}{6.035} & \multirow{2}{*}{$1.778-20.488$} & \multirow{2}{*}{0.012} \\
\hline & Syria & $4(25.00 \%)$ & $19(5.23 \%)$ & & & \\
\hline
\end{tabular}

\section{Discussion}

Thrombocytopenia is a recognized complication of advanced liver disease related to CHB infection; however, the association is not well understood with uncomplicated HBV infection. To the best of our knowledge, this is the first insight study about the frequency of thrombocytopenia and few variables associated with CHB patients. In this study, comparing the characteristics of HBV patients and control group, significant association was found between HBV and younger age, cigarette smoking, and alcohol consumption. The younger age group in this study is in favor to other studies (El-Hazmi, 2004), where such age group are more prone to having HBV through intimate contact and sexual practices as they are more active in their life. In the current study, although HBV was more frequent among males, the difference was not statistically significant. Similarly, the majority of HBV cases reported were among men aged 25-44 years (Van Buren and Schaffner, 1991). In our study, the higher rate of smoking and alcoholism among HBV patients were similar to the findings of other studies (Gitto et al., 2014). Singal et al. (Singal and Anand, 2007) stated that alcoholic people are more prone to HBV 
infection because they are more likely to demand hospitalization including blood transfusion. In addition to this, risky sexual practices are more common among alcoholics. Although HBV was more frequent among Syrian patients, the finding was not statistically significant. The seroprevalence of HBV is higher in the Syrian population ranging from intermediate to high (Bashour and Muhjazi, 2016), whereas, in Iraq, it is ranging from low to intermediate (Alsamarai et al., 2016; Merza et al., 2014; Merza et al., 2016). Hence, the frequency of HBV infection is higher among Syrian patients.

In the present study, chronic active hepatitis $\mathrm{B}$ was strongly associated with an increased rate of thrombocytopenia. This finding is paramount as it is statistically significant $(P=0.042)$ in the absence of liver complications such as liver cirrhosis or splenomegaly. Correspondingly, a large cohort study by Joo et al., found an increased incidence of thrombocytopenia among HBV patients in comparison to those in the control group (Joo et al., 2017). Similarly, another study from Iran documented a significant association between chronic active HBV and thrombocytopenia (Behnava et al., 2006). In contrast, other studies did not find this association (Nwokediuko and Ibegbulam, 2009). Several studies have shown a link between viral infections such as hepatitis A, B, C viruses and thrombocytopenia through directly inhibiting the growth and differentiation of human bone marrow progenitor cells in vitro (Zeldis et al., 1986). However, this link is more prominent in patients with HCV infection due to direct bone marrow suppression (Wang et al., 2004). As hypersplenism resulting from liver cirrhosis was excluded in our patients, the cause of thrombocytopenia is due to other mechanisms. Therefore, it is important to consider CHB in the differential diagnosis of patients presenting with isolated thrombocytopenia.

Considering comparative analysis between thrombocytopenia with and without $\mathrm{HBV}$, the only independent risk factors associated with thrombocytopenia were older age $(49.56 \pm 17.16$ vs $32.92 \pm 13.94)$ and Syrian nationality (Table 3). Older age has been found to be a risk factor for developing thrombocytopenia in chronic viral hepatitis patients, particularly HCV infection, despite non-advanced liver diseases (Wang et al., 2004). It seems that cumulative effect of the infection duration on older aged patients with chronic HBV is a potential factor offering sufficient time for developing thrombocytopenia. The Syrian nationality was a predictor of thrombocytopenia in HBV patients. This finding can be explained by a higher prevalence of HBV infection in Syria as discussed previously. A significant association was not found between thrombocytopenia in HBV patients and health related behaviors i.e. cigarette smoking and alcohol consumption. Hence, such variables are unlikely to be implicated in the mechanism of thrombocytopenia in patients with chronic HBV.

There are certain limitations in this study. First, the sample size was small. Second, the extent of liver disease was assessed according to clinical, laboratory and ultrasound examinations, but liver biopsy was not performed in the majority of cases for precise evaluations.

\section{Conclusions}

Younger age, cigarette smoking, and alcohol consumption were independent risk factors for CHB infection. Chronic active hepatitis B is strongly associated with thrombocytopenia. As hypersplenism resulting from liver cirrhosis was excluded in our patients, the cause of thrombocytopenia is due to other mechanisms. Therefore, it is important to consider CHB in the differential diagnosis of patients presenting with isolated thrombocytopenia. Older age and Syrian nationality were predictors for developing thrombocytopenia in chronic active HBV infection.

Further prospective studies with larger sample sizes that include other variables such as body mass index, HDV co-infection... etc are warranted to better understand the association between the two clinical conditions.

\section{Acknowledgements}

We would like to thank all the staff of the viral hepatitis clinic of ATH, Duhok province for their kind support in this study.

\section{Conflict of interest}

None to declare.

\section{References}

Alsamarai AM, G Abdulrazaq, A Fatah and A Alobaidi, 2016. Seroprevalence of Hepatitis B Virus in Iraqi Population. J. Vaccines Immunol., 2016.

Bano S, J Qureshi, A Raza and KZ Hashmi, 2016. Thrombocytopenia as a Clinical Manifestation of Hepatitis C Among Patients With a Positive Anti-HCV Test. International Journal of Infection, 3. 
Bashour H and G Muhjazi, 2016. Hepatitis B and C in the Syrian Arab Republic: a review. EMHJ-Eastern Mediterranean Health Journal, 22: 267-273.

Behnava B, S-M Alavian and M AHMADZADASL, 2006. The prevalence of thrombocytopenia in patients with chronic hepatitis B and C. Hepatitis monthly. 2006: 67-69.

Cacoub P, D Saadoun, M Bourlière, H Khiri, A Martineau, Y Benhamou, et al., 2005. Hepatitis B virus genotypes and extrahepatic manifestations. J. Hepatol., 43: 764-770.

Dunn C, D Peppa, P Khanna, G Nebbia, M Jones, N Brendish, RM Lascar, D Brown, RJ Gilson, RJ Tedder, GM Dusheiko, M Jacobs, P Klenerman and MK Maini, 2009. Temporal analysis of early immune responses in patients with acute hepatitis B virus infection. Gastroenterology, 137: 1289-1300.

El-Hazmi MM, 2004. Prevalence of HBV, HCV, HIV-1, 2 and HTLV-I/II infections among blood donors in a teaching hospital in the Central region of Saudi Arabia. Saudi Med. J., 25: 26-33.

European Association for the Study of the Liver (EASL), 2017. Clinical Practice Guidelines on the management of hepatitis B virus infection. J. Hepatol., 67: 370-398.

Gauer RL and MM Braun, 2012. Thrombocytopenia. American family physician. 85

Gitto S, G Vitale, E Villa and P Andreone, 2014. Update on alcohol and viral hepatitis. J. Clin. Transl. Hepatol., 2: 228.

Joo EJ, Y Chang, JS Yeom, YG Lee and S Ryu, 2017. Hepatitis B infection is associated with an increased incidence of thrombocytopenia in healthy adults without cirrhosis. J. Viral Hepatitis, 24: 253-258.

Marcellin P, C Castelnau, M Martinot-Peignoux and N Boyer, 2005. Natural history of hepatitis B. Minerva Gastroenterol Dietol., 51: 63-75.

Merza M, W Hassan and A Muhammad, 2014. Frequency of HBV and HCV among patients undergoing elective surgery in a tertiary care referral Hospital in Duhok, Iraqi Kurdistan. JMSCR, 2: 1810-1815.

Merza MA, SM Haji, AM Alsharafani and SU Muhammed, 2016. Low prevalence of hepatitis B and C among tuberculosis patients in Duhok Province, Kurdistan: Are HBsAg and anti-HCV prerequisite screening parameters in tuberculosis control program? Int. J. Mycobacteriol., 5: 313-317.

Mitchell O, DM Feldman, M Diakow and SH Sigal, 2016. The pathophysiology of thrombocytopenia in chronic liver disease. Hepat Med., 8: 39-50.

Nwokediuko SC and O Ibegbulam, 2009. Quantitative platelet abnormalities in patients with hepatitis B virusrelated liver disease. Gastroenterology Research, 2: 344.

Schweitzer A, J Horn, RT Mikolajczyk, G Krause and JJ Ott, 2015. Estimations of worldwide prevalence of chronic hepatitis B virus infection: a systematic review of data published between 1965 and 2013. The Lancet, 386: 1546-1555.

Singal AK and BS Anand, 2007. Mechanisms of synergy between alcohol and hepatitis C virus. J. Clin. Gastroenterol., 41: 761-772.

Van Buren RC and W Schaffner, 1991. Hepatitis B virus: a comprehensive strategy for eliminating transmission in the United States through universal childhood vaccination. Recommendations of the Immunization Practices Advisory Committee (ACIP). MMWR Recomm. Rep., 40: 1-19.

Wang C-S, W-J Yao, S-T Wang, T-T Chang and P Chou, 2004. Strong association of hepatitis C virus (HCV) infection and thrombocytopenia: implications from a survey of a community with hyperendemic $\mathrm{HCV}$ infection. Clin. Infect. Dis., 39: 790-796.

Zeldis J, H Mugishima, H Steinberg, E Nir and R Gale, 1986. In vitro hepatitis B virus infection of human bone marrow cells. J. Clin. Invest., 78: 411-417. 